\title{
On the influence of tree size on the climate-growth relationship of New Zealand kauri (Agathis australis): insights from annual, monthly and daily growth patterns
}

\author{
Journal Article \\ Author(s): \\ Wunder, Jan; Fowler, Anthony M.; Cook, Edward R.; Pirie, Maryann; McCloskey, Shane P.J. \\ Publication date: \\ 2013-08 \\ Permanent link: \\ https://doi.org/10.3929/ethz-b-000412576 \\ Rights / license: \\ In Copyright - Non-Commercial Use Permitted \\ Originally published in: \\ Trees 27(4), https://doi.org/10.1007/s00468-013-0846-4
}




\title{
On the influence of tree size on the climate-growth relationship of New Zealand kauri (Agathis australis): insights from annual, monthly and daily growth patterns
}

\author{
Jan Wunder • Anthony M. Fowler • \\ Edward R. Cook • Maryann Pirie • \\ Shane P. J. McCloskey
}

Received: 24 February 2012/Revised: 19 December 2012/Accepted: 9 January 2013/Published online: 1 February 2013

(c) Springer-Verlag Berlin Heidelberg 2013

\begin{abstract}
Many tree-ring-based climate reconstructions are based on the assumption that the climate reaction of trees is independent of their size. Here, we test this assumption for New Zealand kauri (Agathis australis), one of the longest tree ring-based proxies for the El NiñoSouthern Oscillation (ENSO). The most recent kauri chronology contains a large amount of archaeological material, e.g. timber for which the original tree size is often unknown. We analyzed the climate-growth relationship of different-sized kauri in a pristine forest using different temporal scales, i.e. annually, monthly and daily data on
\end{abstract}

Communicated by Y. Sano.

Electronic supplementary material The online version of this article (doi:10.1007/s00468-013-0846-4) contains supplementary material, which is available to authorized users.

J. Wunder $(\bowtie)$

Forest Ecology, Institute of Terrestrial Ecosystems,

Department of Environmental Systems Science,

ETH Zurich, 8092 Zurich, Switzerland

e-mail: wunder@env.ethz.ch

J. Wunder - A. M. Fowler - M. Pirie

School of Environment, The University of Auckland,

Auckland 1020, New Zealand

E. R. Cook

Tree-Ring Laboratory, Lamont-Doherty Earth Observatory

of Columbia University, Palisades, NY 10964, USA

M. Pirie

Department of Statistics, The University of Auckland,

Auckland 1020, New Zealand

S. P. J. McCloskey

Centre de Bio-Archéologie et d'Écologie (UNR 5059 CNRS),

Institut de Botanique, l'Université de Montpellier,

34000 Montpellier, France tree growth and climate conditions. Trees of different life stages exhibited approximately the same seasonal growth peaks during austral spring (October and November). The dormancy period overlaps with the period where weekly air temperature maxima are below ca. $17-18{ }^{\circ} \mathrm{C}$, and where the corresponding daily minima are below ca. $8{ }^{\circ} \mathrm{C}$. However, both correlation functions between annual growth and seasonal climate as well as Kalman filter regressions between daily growth and climate conditions suggest an influence of tree size on the climate-growth relationship for kauri. Smaller trees (DBH $<40 \mathrm{~cm}$ ) contain weaker climate signals than larger trees. Therefore, the precautionary stripping of near-pith material (first $20 \mathrm{~cm}$ ) from kauri chronologies may result in more uniform responses to climate forcing and thus enhance the reliability of long-term climate reconstructions.

Keywords Seasonal growth characteristics .

Climate-growth relationship - Dendroclimatology ·

Dendrochronology $\cdot$ Dendrometer bands · Kalman filter regression $\cdot$ Correlation functions

\section{Introduction}

The relationship between climate factors and tree growth is the key to any dendrochronological analysis. However, detailed knowledge about this climate-growth relationship and its variation with tree age/size is often missing. Relatively few studies address the scaling effects of tree age (Carrer and Urbinati 2004; Esper et al. 2008; Viera et al. 2009; Dorado Liñán et al. 2011) and fewer still focus on tree size effects (De Luis et al. 2009). In the absence of scaling information, dendroclimatologists are obliged to assume that different-sized trees show similar sensitivity to 
climate forcing. Hence, most tree-ring-based climate reconstructions are based on a pure statistical correlation between tree rings (of different-sized trees) and climate data during the period of instrumental records (Vaganov et al. 2011). In particular, climate reconstructions based on a large amount of archaeological material (Büntgen et al. 2011) rely on this assumption since the original size of the timber yielding trees is often unknown.

One of the most important tree-ring-based climate proxies of the Southern Hemisphere is Agathis australis (kauri), an endemic conifer from northern New Zealand (Cook et al. 2006). Kauri is being used for multi-century reconstructions of the activity of the El Niño-Southern Oscillation (ENSO) with wider (smaller) rings usually formed during El Niño (La Niña) events (Fowler et al. 2008, 2012). Interestingly, wide kauri rings are often laid down in years with cool and dry springs (Buckley et al. 2000). The mechanism behind this counter-intuitive statistical relationship remains largely unclear although it has been hypothesized that cloud coverage anomalies during ENSO events (Warren et al. 2007) may alter the incoming solar radiation and subsequently tree growth (Fowler et al. 2000). This (unknown) climate-growth relationship may be age and/or size dependent because kauri changes its tree architecture during different life stages, i.e. between juvenile monopodial growth of young trees to sympodial growth of old, large, canopy emergent trees (Ecroyd 1982). In addition, leaf morphology changes with life stage, whereby the more planar foliage of young trees is most efficient for light interception (Niinemets et al. 2005). Therefore, the usage of archaeological material (from kauri of unknown size) for chronology building and subsequent climate reconstructions warrants a careful analysis of the climate-growth relationship and potential scaling effects with tree size. Any significant size-dependent climategrowth relationship may weaken the climate signal of a composite chronology, particularly when (1) the climate response is strongly size dependent and (2) the proportion of small versus large-tree material changes considerably over time.

Few studies have addressed the climate-growth relationship of kauri in New Zealand. Bieleski (1959) used monthly temperature data and phenological observations from kauri forests of the Waitakere Ranges (Mirams 1951) to suggest a threshold of $17.5^{\circ} \mathrm{C}$ of weekly maximum temperatures to break the dormancy of kauri in that region. Palmer and Ogden (1983) undertook monthly to bimonthly dendrometer measurements during the 1980/81 growing season, reporting a peak in seasonal growth during the austral summer (January to February) and a possible drought-induced growth cessation at two mid-altitude sites. In contrast, Fowler et al. (2005) found an earlier peak in kauri growth in austral spring and observed no differences between different-sized kauri. Their findings are based on monthly dendrometer measurements in the Waitakere Range over four consecutive years (1996/1997-1999/ 2000). However, both dendrometer studies are limited by the coarse temporal resolution (monthly to bi-monthly growth data) and the absence of conjointly recorded (micro-) climate conditions.

In this paper, we are expanding the monthly climategrowth analyses of different-sized kauri by an annual and daily perspective. Both levels complement our understanding of the climate-growth relationship of kauri in different ways: the coarser annual resolution (tree rings) allows for a longterm analysis across the entire twentieth century at the level of correlation functions (non-process level); the finer daily resolution is potentially critical to our ecophysiological understanding of the xylogenesis (process level).

Specifically, we will (1) use annual tree-ring-data to analyze the climate signal of small-tree versus large-tree chronologies; (2) revisit and expand previous analyses using monthly resolution; and (3) use daily resolved growth and climate data during one growing season (xylogenesis) to address the following questions:

- What are the seasonal growth characteristics of different-sized kauri?

- How similar are different-sized kauri (with different architecture) in their response to climate conditions?

- What are the implications for the stored climate signals and eventually for climate reconstructions?

\section{Materials and methods}

\section{Study site}

The study site for all analyses was Huapai Scientific Reserve (HSR), ca. $90 \mathrm{~m}$ a.s.1., in the northern Waitakere Range, ca. $30 \mathrm{~km} \mathrm{NW}$ of Auckland (Fig. 1a). The reserve comprises ca. 15 ha of well-preserved kauri broadleafforest (Thomas and Ogden 1983) and is located near the centre of kauri's natural growth range in northern New Zealand (Ecroyd 1982). Soils are Parau clays on andesitic tuffs (Thomas and Ogden 1983). The site is characterized by a warm temperate climate with humid summers and mild winters; maximum monthly temperatures and minimum precipitation coincide in January and February, minimum monthly temperature and maximum monthly precipitation in July (Supporting Information Fig. S2.1).

The kauri forest analyzed here is characterized by a species-rich forest layer of shrubs, small trees, tree ferns and palms. For the larger trees (diameter at breast height, $\mathrm{DBH}>20 \mathrm{~cm}$ ), kauri is the dominating canopy species. This dominance of kauri is also evident from its large basal 

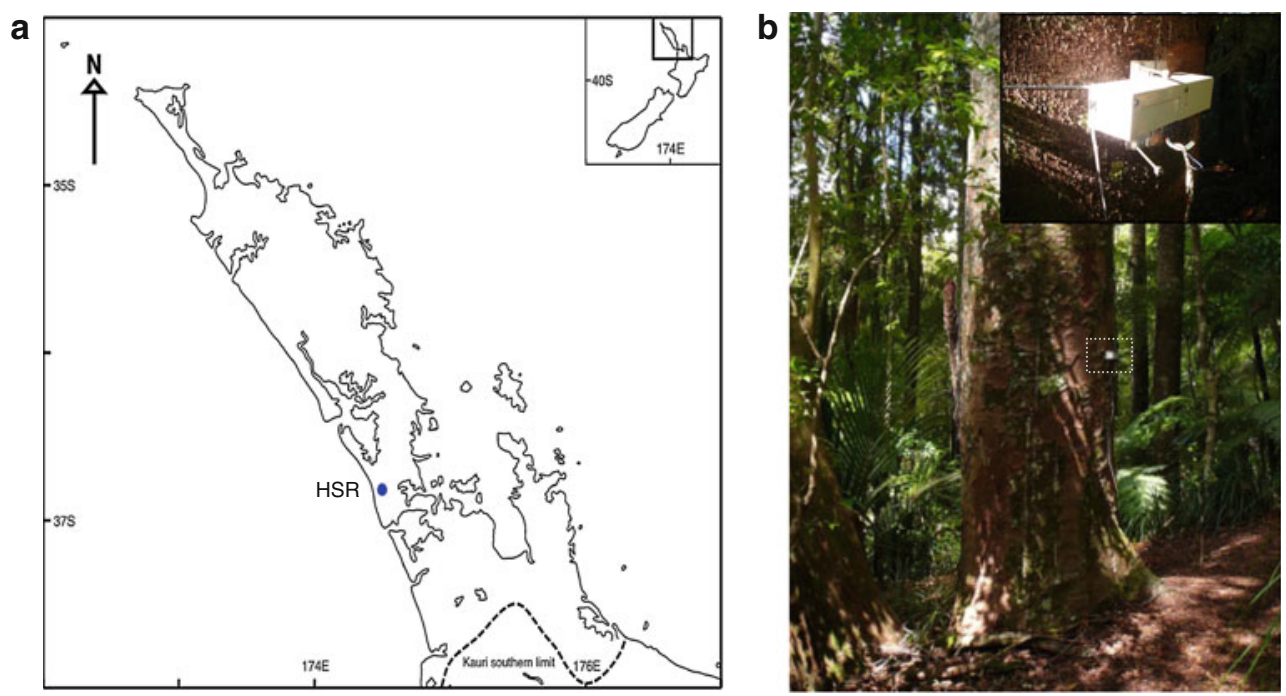

Fig. 1 a Location of Huapai Scientific Reserve (HSR) in New Zealand and the kauri growth range north of the ca. $38^{\circ} \mathrm{S}$ (dashed line), b Mature kauri $(\mathrm{DBH}=1.04 \mathrm{~m})$ with automatic band dendrometer (white "box"-Agricultural Electronics Corp., Tucson, USA)

area (74.8 of a total of $94.4 \mathrm{~m}^{2} / \mathrm{ha}$, Wunder et al. 2010). Kauri is currently present in all size classes and with ca. 770 individuals/ha is also the most abundant tree species. Further details of HSR and of the study plot can be found in Fowler and Boswijk (2001) and Wunder et al. (2010).

Kauri growth and climate measurements

We used data at three different temporal scales—annual, monthly and daily resolved data on tree growth and climate conditions. Annual data covers the period from 1900 to 1992, monthly data the growing seasons from 1997 to 2000 and 2008/09 and daily data the growing season 2008/09.

\section{Annual resolution (1900-1992)}

Growth data The tree-ring chronology of HSR (Fowler and Boswijk 2001) was split into a small-tree and a large-tree chronology using a threshold of $20 \mathrm{~cm}$ for the estimated distance to the pith. Thus, the small-tree chronology represents trees up to ca. $40 \mathrm{~cm} \mathrm{DBH}$, the large-tree chronology the remaining larger trees (Supporting Information S1).

Climate data Seasonal temperature and precipitation data from 1900 to 1992 were derived from the Mangere Climate Station, Auckland (National Institute of Water and Atmosphere Research NIWA, New Zealand), ca. $32 \mathrm{~km}$ SE of HSR; data on the Southern Oscillation Index (SOI) were obtained from the Australian Bureau of Meteorology (BOM).

\section{Monthly resolution (1997-2000, 2008/09)}

Growth data We transformed our growth measurements during 2008/09 (see below) into monthly resolution and expanded them using seasonal growth data collected at HSR for the very same trees from 1997 to 2000 (Fowler et al. 2005). Thus, for every tree measured in 2008/09, we also have a (small) part of its seasonal growth history, i.e. monthly resolved growth data covering the seasons 1997-2000.

In addition, we estimated the period of xylem formation during 2008/09 for a subset of the analyzed trees and their competitors (20 trees total) using wood anatomical measurements of newly formed tracheids: every month up to six micro-cores were extracted from 11 small trees (DBH $<42 \mathrm{~cm}$ ) using a micro corer (WSL Birmensdorf, Switzerland, diameter $2.5 \mathrm{~mm}$, length $10 \mathrm{~mm}$, for details see Forster et al. 2000). For 9 larger trees with thicker bark (DBH $>42 \mathrm{~cm}$ ), the micro corer had to be replaced by a standard corer (diameter $4.3 \mathrm{~mm}$, length ca. $100 \mathrm{~mm}$, two cores per tree) that was used on a bi-monthly time scale (to compensate for the larger impact). This allowed us to approximately distinguish calendar months with xylem growth from the dormancy period where any minor circumference changes were related to non-growth processes, such as rehydration or bark swelling (Schweingruber 1996). The relatively modest sampling scheme is a consequence of the high protection status of kauri and ethical concerns.

Climate data Monthly temperature and precipitation data from 1962 to 2011 were derived from the Auckland Airport station (National Institute of Water and Atmospheric Research NIWA, New Zealand), ca. $34 \mathrm{~km}$ SE of HSR.

Daily resolution (2008/09)

Growth data We installed automatic band dendrometers (Agricultural Electronics Corp., Tucson, USA, Fig. 1b) on 
14 different-sized kauri (18.9-174.2 cm DBH) in a $50 \times 40 \mathrm{~m}$ research plot of HSR (Wunder et al. 2010). On each of these trees, one dendrometer band was installed at breast height to record changes in tree circumference every 30 min during the austral growing season 2008/2009. Thirteen of the installed bands recorded reliable data. Trees were grouped into four size classes: very small $(<25 \mathrm{~cm} \mathrm{DBH}$, $n=2)$; small $(25-40 \mathrm{~cm} \mathrm{DBH}, \quad n=3)$; intermediate (40-70 $\mathrm{cm} \mathrm{DBH,} n=4)$ and large ( $>70 \mathrm{~cm} \mathrm{DBH,} n=5)$. The site was visited weekly to check the proper alignment of the bands and potential disturbances, such as resin exudations and bark flaking close to the bands. From October 3 to April 21, we obtained an almost continuous record (missing values: ca. $1.27 \%$ of the data), with just a few single missing data points related to instrument failures and some rare data loss during night time, likely caused by insufficient energy supply from the batteries. Missing values were estimated using linear interpolation (for one missing value) or spline fitting (for several missing values).

Climate data We recorded daily air temperature, soil moisture and solar radiation under canopy and in open sky using two climate stations with the following high-resolution sensors (30 min resolution, Supporting Information Fig. S3.2): Air temperature (Onset Hobo, USA, $2 \mathrm{~m}$ above ground) and soil moisture (TDR, Campbell Scientific Inc., Logan, USA, 0-30 cm below ground) were recorded at a station established in 2008 under canopy at the plot centre in HSR. Photosynthetic active solar radiation (Quantum Sensor, Campbell Scientific Inc., Logan, USA, 2 m above ground) was recorded at an open sky station, established in $2006 \mathrm{ca} .5 \mathrm{~km} \mathrm{~N}$ of HSR.

\section{Statistical analysis}

\section{Annual resolution (1900-1992)}

Correlation functions were calculated between the annual growth of kauri and seasonal climate anomalies (Fowler et al. 2000); the level of significance was estimated using bootstrapped $t$ statistics (Biondi and Waikul 2004).

\section{Monthly resolution (1997-2000, 2008/09)}

Monthly growth data from four seasons (this study and Fowler et al. 2005) were used to elucidate the inter-annual variability of monthly kauri growth and its relation to anomalous monthly precipitation. "Anomalous" was defined as the $10 \%(n=5)$ wettest resp. driest months from the 50-year instrumental record from Auckland Airport station (1962-2011).

\section{Daily resolution (2008/09)}

Seasonal growth of individual trees was recorded as absolute growth ( $\Delta$ circumference) and transformed into stem radial increment (SRI) according to Downes et al. (1999) and Deslauriers et al. (2003), i.e. the difference between the maximal morning expansion (from 0000 to 1200 AM) of two consecutive days, defined as previous and current calendar day. By definition, SRI was assigned to the current calendar day. Furthermore, all negative SRI values were set to zero (Deslauriers et al. 2003). Thermal expansion of the bands (hastalloy 276, thermal coefficient of expansion: $11.2 \mu \mathrm{m} \mathrm{m}^{-1} \mathrm{~K}^{-1}$ ) was corrected using the conjoint air temperature measurements at the same temporal resolution. No further attempt was made to correct for swelling and shrinkage of stem and bark nor for the bark growth, i.e. it was assumed that the derived SRI time series do mainly reflect xylem growth.

For the analysis of the climate-growth relationship, we initially used multiple ordinary least square (OLS) regression. However, during the model selection stage, we often encountered critical collinearity and residual autocorrelation (Supporting Information S3). Therefore, we applied the Kalman filter (Kalman 1960) that has been used to detect time-varying climate responses in interannual tree ring series (e.g. Visser 1986; Visser and Molenaar 1988; Cook and Johnson 1989; Visser et al. 2010). Here, we apply this approach at an intra-annual level to elucidate the relationship between environmental conditions and seasonal tree growth. The Kalman filter approach goes beyond the traditional multiple ordinary least square regression (with explanatory variables that are forced to be constant over time) since it allows for both time-dependent and time-independent climatic responses (see Supporting Information S3 for a method comparison). This flexibility makes systematic departures from the fitted values less likely, resulting in reduced residual autocorrelation. The Kalman filter regression coefficients can be interpreted in the same way as for the ordinary least square regression, i.e. a significant effect $(p \leq 0.05)$ occurs when the mean estimate $\pm 1.96 \mathrm{SE}$ deviates from zero ( $p \leq 0.1,1.645 \mathrm{SE})$. In case of time-dependent climate responses, the coefficients may differ for each time step, in our case day by day. For details on the Kalman filter and the corresponding maximum likelihood estimation, see Harvey $(1984,1989)$.

For the Kalman filter regression, the response variable is SRI. Since larger trees typically show larger SRI, we standardized all values to relative daily SRI (percentage of annual growth on any given day). These time series were then averaged for the groups 'very small', 'small', 'medium', 'large' and 'all trees' and subsequently normalized to improve model convergence. Explanatory variables are the daily means of air temperature, soil moisture and photosynthetic active solar radiation, calculated separately for the current and previous day. All explanatory variables were standardized to relative values, e.g. soil moisture 
values ranged from 0 (seasonally driest condition) to 1 (field capacity), and subsequently normalized.

We calculated a set of candidate models for the complete data set (comprising all trees) with all possible combinations of the three climate variables (air temperature, soil moisture and photosynthetic active solar radiation) for the current and previous day. Thus, the least complex models contain only one variable, and the most complex six (three climate variables for both the current and previous day). For model selection, we used the Akaike Information Criterion corrected for small sample sizes (AICc, Hurvich and Tsay 1989; Van Deusen 1990). The model structure with the highest performance was fitted to the size cohorts 'very small', 'small', 'medium' and 'large' trees. Model performance was further assessed by calculating Pearson product moment correlation coefficients between the fitted and observed values of the Kalman filter regression.

Statistical analyses were performed using $\mathrm{R}$, a language and environment for statistical computing ( $R$ version 2.12.2, R Development Core Team 2011), the Kalman filter regression was done using the KalregX software (Cook ER, unpublished).

\section{Results}

Kauri growth characteristics

\section{Annual resolution (1900-1992)}

For all analyzed climate variables, the large-tree chronology contains a stronger climate signal than the small-tree chronology that is characterized by a low correlation between annual growth and climate conditions (Fig. 2). For autumn temperature, even the direction of the correlation differs with large (small) trees showing a significant positive (negative) correlation between growth and temperature (Fig. 2).

\section{Monthly resolution (1997-2000, 2008/09)}

The growth timing of the 13 analyzed trees does not differ much with tree size-all trees grow mostly in October and November (Fig. 3). During the four observation years, small and large trees show similar monthly growth patterns that seem largely to persist during precipitation anomalies (Fig. 3). For example, dry anomalies seem not to cause a unilateral disadvantage of smaller trees that are characterized by a lesser-developed root system.

\section{Daily resolution (2008/09)}

Absolute circumference changes during the months of xylem growth (October 2008-April 2009) showed a high inter-tree variability and ranged from $1.58 \mathrm{~mm}$ for one of the smallest trees to $8.40 \mathrm{~mm}$ for the largest tree (Fig. 4). In contrast, relative growth increments were fairly similar: most of the trees were reaching $50 \%$ of the annual growth in October and November alone (Fig. 4). However, the larger trees $(\mathrm{DBH}>70 \mathrm{~cm})$ were characterized by a high inter-tree variability with some trees reaching $50 \%$ growth by the end of October, but others as late as the end of December. Most trees show considerably reduced growth in early and mid summer ("plateau phase") and also some shrinkage followed by a minor growth peak at the end of the summer, i.e. in March (Fig. 4).

\section{Period of xylem formation}

\section{Monthly resolution (1997-2000, 2008/09)}

The period of xylem growth corresponds approximately to the calendar months October 2008-April 2009, i.e. the analyzed micro-cores and increment cores (Fig. 5) consistently showed no xylem formation in early spring (September) and a growth cessation in late autumn (Supporting Information Table S2.1). Thus, circumference increments in September may be (mostly) related to rehydration processes, and changes in circumference from May on are possibly related to bark swelling due to the starting winter precipitation.

Xylem growth coincides with weekly maximum air temperatures exceeding ca. $17.5^{\circ} \mathrm{C}$ (Fig. 6): a threshold temperature that is consistent with the findings of Bieleski (1959) for mature trees and seedlings. This period is also characterized by daily minimum air temperatures above ca. $8{ }^{\circ} \mathrm{C}$ (Fig. 6).

\section{Climate-growth modelling}

\section{Daily resolution (2008/09)}

The best performing models comprise only two variables: the air temperature and soil moisture of the previous day (Fig. 7). The climate response of different-sized kauri is very similar with these two environmental factors having a highly time-dependent influence on the seasonal tree growth: the higher the air temperature and soil moisture of the previous day, the higher the SRI of the current day (Fig. 7). The most significant correlations were found for the austral spring (October and November) and to a lesser extent roughly at the end of summer (February). During December and January, trees of most size classes were not showing any significant reaction to air temperature and soil moisture. Deviations from this general pattern are the consistent, almost time-independent positive correlations 

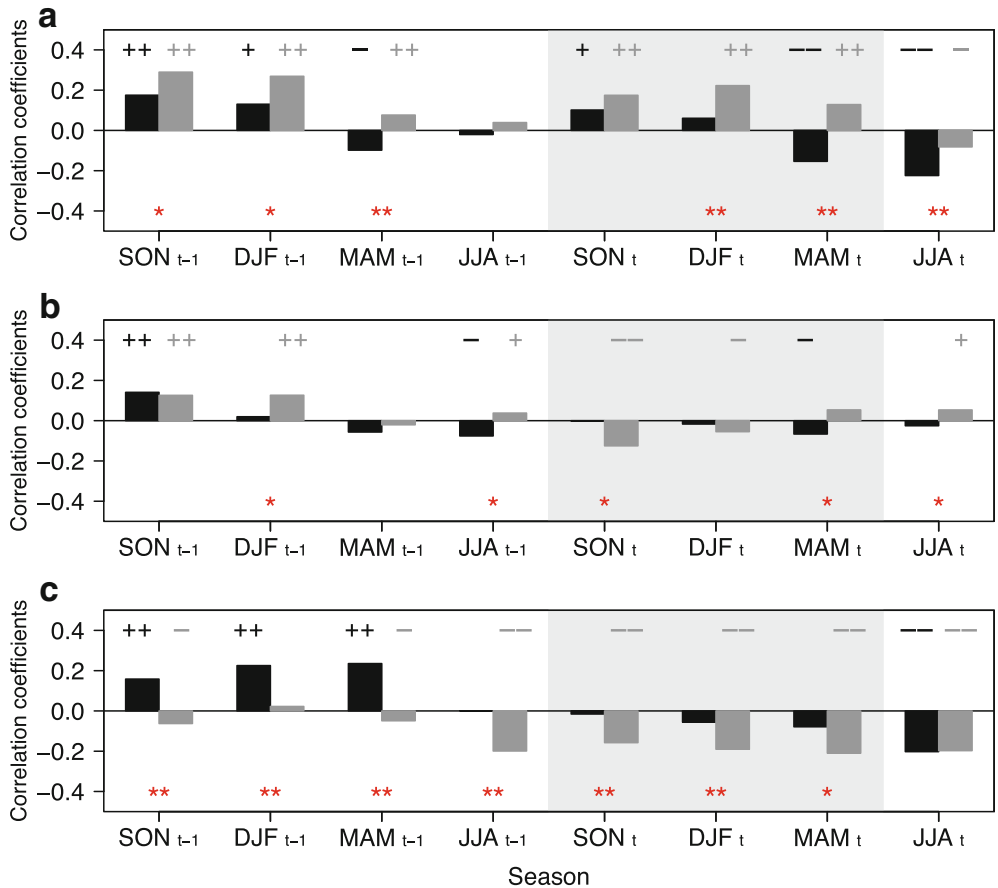

Fig. 2 Kauri growth characteristics-annual time scale. Correlation function between annual growth of small (black) versus large (grey) trees and a temperature, b precipitation and c SOI. Significant correlations are indicated for both chronologies with a grey or black positive/negative sign, significant differences between the chronologies with a red asterisk. Significance levels: Two signs $(++/--/ * *)$ for $p<0.001$, one sign $(+/-/ *)$ for $0.001<p<0.05$. SON: austral spring (September, October, November); DJF: austral summer (December, January, February); MAM: austral autumn (March, April, May); JJA: austral winter (June, July, August) of current year $(t)$ and previous year $(t-1)$. See also Supporting Information Table S1

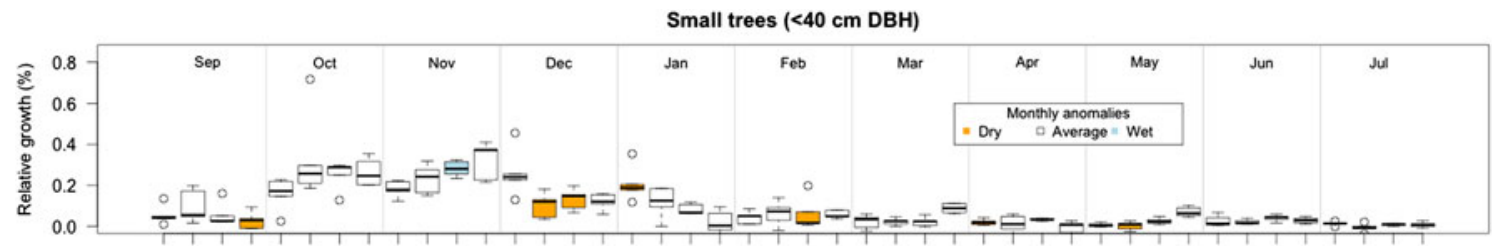

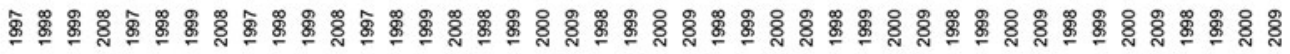

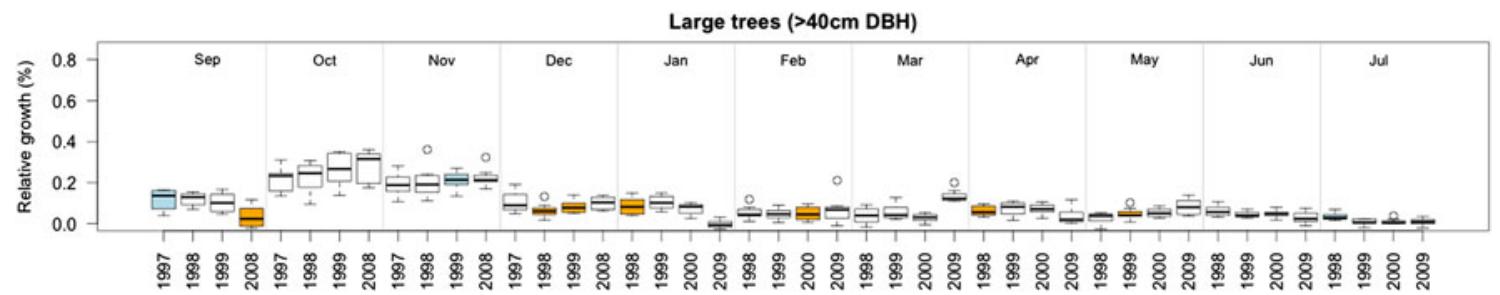

Fig. 3 Kauri growth characteristics - monthly time scale. Relative monthly growth (fraction of annual growth) during 1997-2000 and 2008/09 for the 13 analyzed trees, split in two size classes (using the $40 \mathrm{~cm} \mathrm{DBH}$ threshold). Box colours refer to anomalous monthly

between growth and soil moisture for the smaller trees (Fig. 7). For the complete data set (all size classes), the correlation between observed and fitted values was $r=0.593$, the highest performance was achieved for trees of intermediate size $(r=0.662)$, the lowest for smaller precipitation whereby "anomalous" was defined as the $10 \%$ driest $(n=5)$ resp. $10 \%$ wettest $(n=5)$ months of the precipitation record from Auckland Airport 1962 to 2011 ( $n=50$ years). See Fig. S2.2 for a long-term distribution of the anomalies

trees $(r=0.452)$. The residuals of the best performing models for every single size class and the complete data set were not autocorrelated $(p<0.05$, ranked version of von Neumann's ratio test for randomness, Bartels 1982, Supporting Information Table S3.1). 

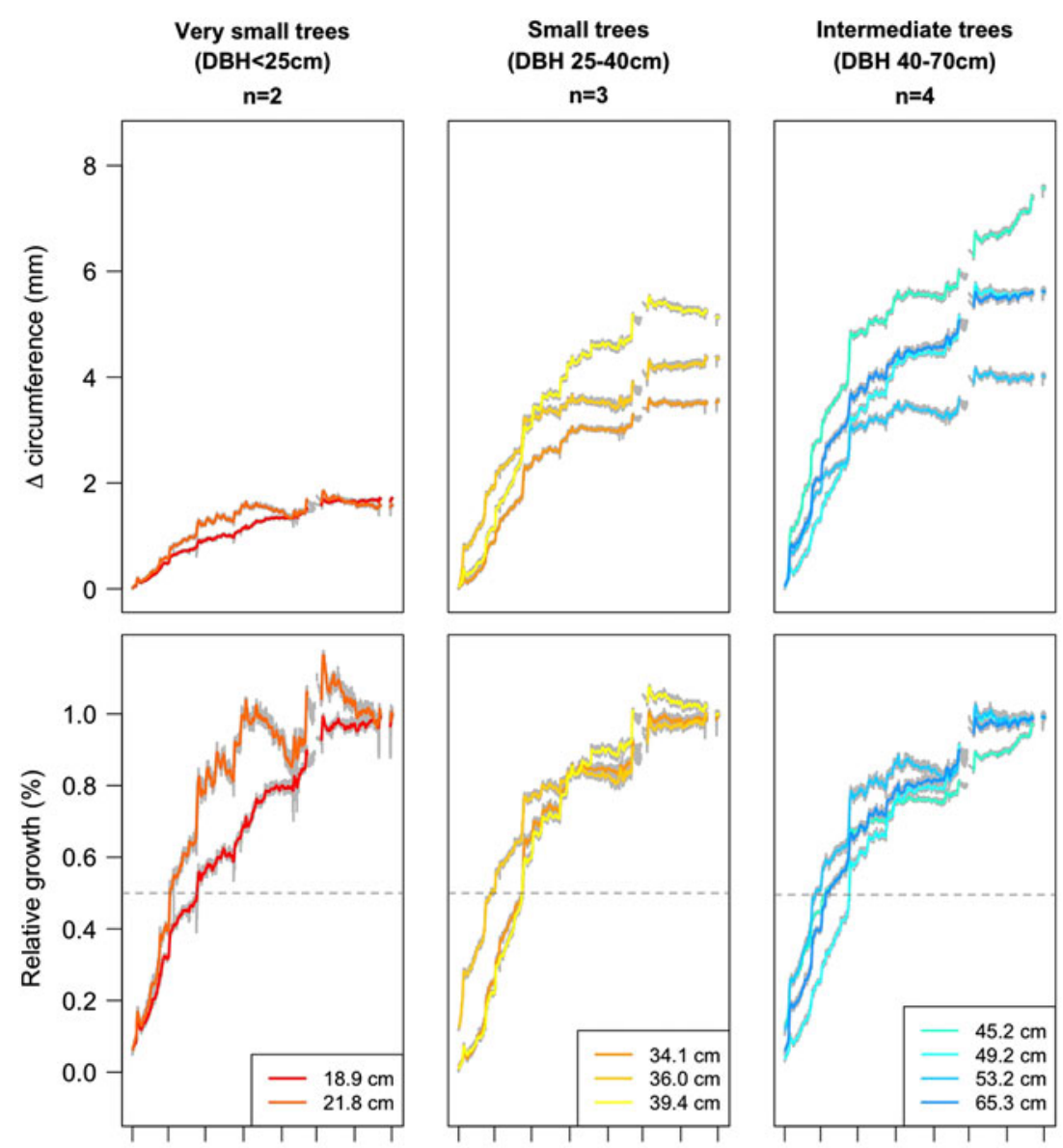

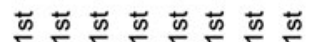

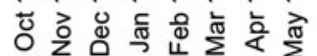

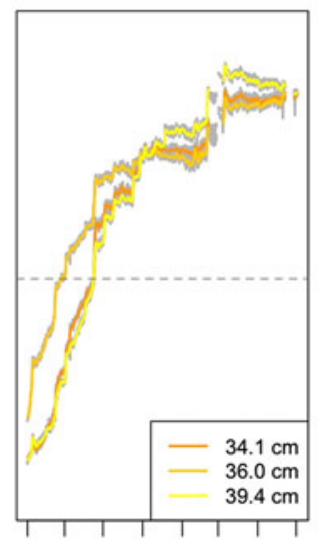

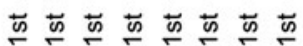

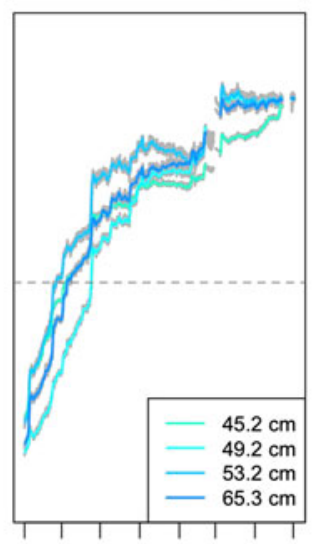

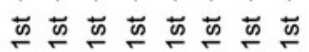

Large trees

(DBH $>70 \mathrm{~cm}$ )
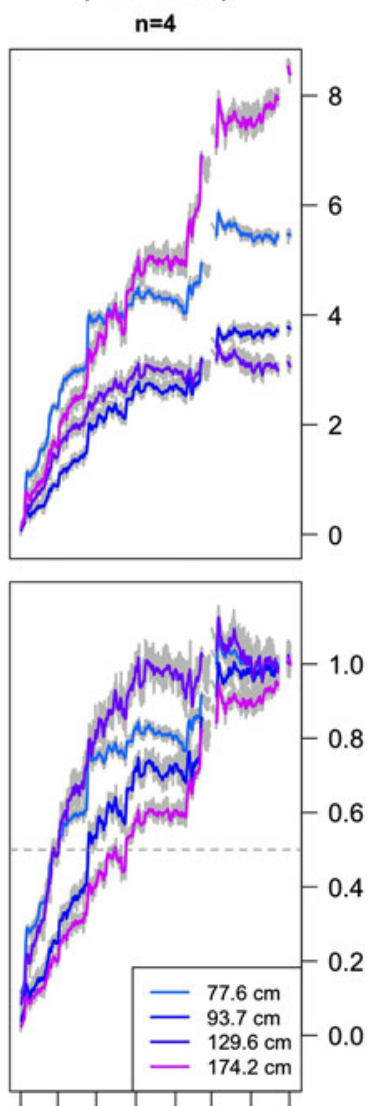

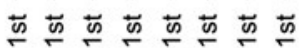

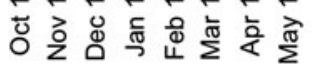

\section{$2008 / 2009$}

Fig. 4 Absolute and relative growth of the analyzed trees. Absolute growth: daily growth (in colours) and 30-min growth records (in grey). Relative growth: $0=1$ st day of the growing season; $1=$ last day of the growing season

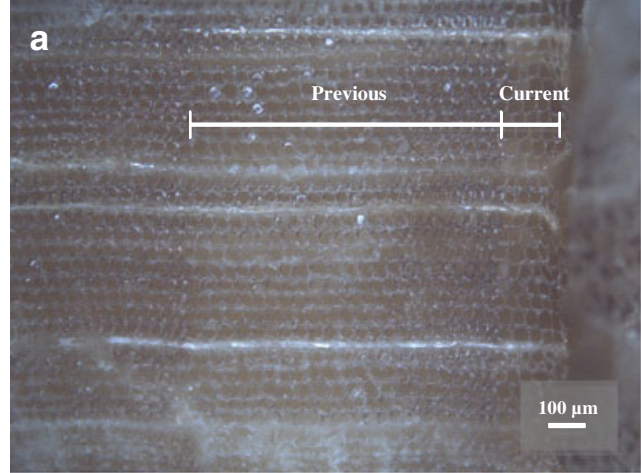

Fig. 5 Wood anatomical examinations. a Early stage of cambial growth (exemplified by one (out of six) micro-cores taken in October 2008 from tree 1027, DBH $24.9 \mathrm{~cm}$ ). b Completed stage of cambial growth (exemplified by one (out of six) micro-cores taken in June

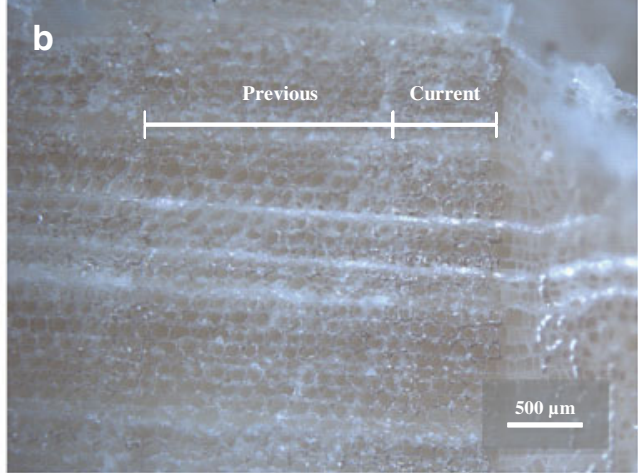

2009 from tree 1019, DBH $21.4 \mathrm{~cm})$. White bars indicate current and previous year xylem growth (Photos: McCloskey SPJ, Olympus BXFM reflected light stereo microscope) 
Fig. 6 Temperature thresholds and dormancy of kauri. Black solid lines maxima and minima of weekly air temperature $(2 \mathrm{~m}$, under canopy). Grey solid line half-hourly air temperature records (2 m, under canopy). Vertical dashed lines beginning and end of xylem growth (estimated from micro-cores). Red dashed line $17.5^{\circ} \mathrm{C}$ threshold of weekly air temperature maxima for breaking the dormancy of kauri (Bieleski 1959). Cross-hatched areas indicate uncertainties associated with the estimation of the xylem growth period (see text)

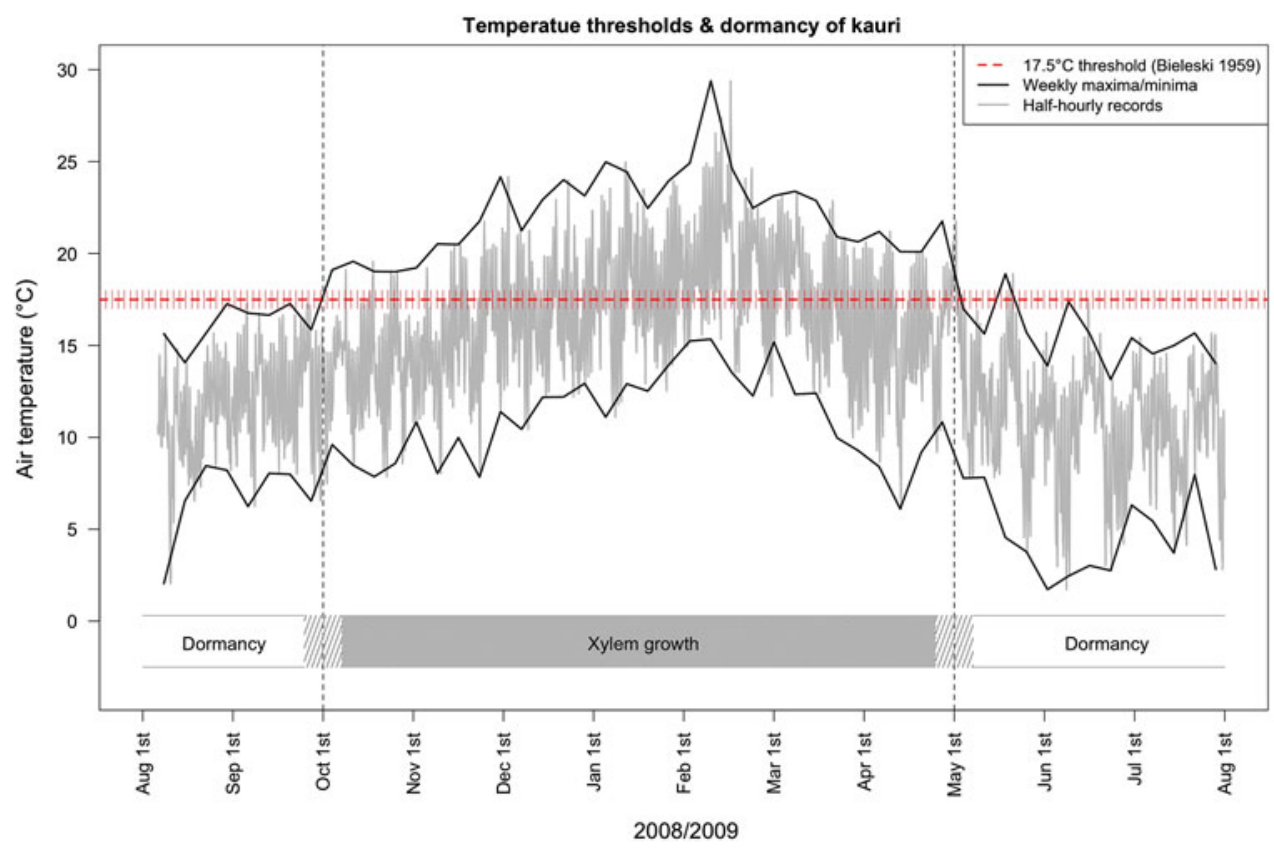

\section{Discussion}

Kauri growth characteristics

The generally weaker climate signal of the small-tree chronology is consistent with the previous findings that inter-tree correlations exhibit strong dependence on tree size (Fig. 5 in Fowler et al. 2004). The stronger correlations associated with larger trees is expected given the previously noted marked changes in tree morphology between juvenile and mature kauri and the characteristic density-dependent thinning of kauri juveniles. Both factors would be expected to modify and weaken the influence of climate forcing.

Relative growth increments during the growing season do not differ much with tree size: most of the analyzed trees formed $50 \%$ of their annual rings in October and November, i.e. during a period when the New Zealand climate experiences the strongest influence of ENSO events (Gordon 1986; Mullan 1995). This finding is in line with the results of a previous study at HSR, where Fowler et al. (2005) found a similar growth pattern based on monthly circumference measurements. Thus, this work confirms that kauri grows at the "right" time window to directly capture the ENSO signal unlike other tree species like Australia Red Cedar (Toona ciliata) that have proved unsuitable as an ENSO proxy because they are dormant during the austral spring (Heinrich et al. 2009).

The mid-summer period of reduced kauri growth ("plateau phase", Fig. 4) is characterized by reduced soil moisture conditions (Supporting Information, Fig. S3.2) that may hinder or even pause cambial activity. The observed negative circumference change for some trees during this relatively dry period is caused by bark/bole shrinkage and masks the "underlying" xylem growth pattern. To some extent, this artefact was accounted for using only (non-negative) SRI time series (SRI in the sense of Downes et al. 1999 and Deslauriers et al. 2003) for the analysis of the climate-growth relationship.

Xylem formation and temperature thresholds

Kauri growth coincides with the period when weekly maximum air temperature exceeds $17-18{ }^{\circ} \mathrm{C}$ (Fig. 6). Bieleski (1959) found the same threshold in controlled experiments using kauri seedlings and also reports this phenomenon for mature trees:

"It was found that in the Waitakere Ranges, kauri was dormant during the winter and formed resting buds, the spell lasting from late April until late August or September. Temperature data for kauri forest in this area (Mirams 1951) show that the period of dormancy corresponds exactly with the period during which the weekly maximum temperature lies below $17.5^{\circ} \mathrm{C} "$ (Bieleski 1959).

Fig. 7 Kalman filter regression for the top-ranked model with the explanatory variables previous day-air temperature and previous daysoil moisture. Time-dependent influences are shown with timevarying mean estimates. Grey bands confidence interval of the regression weights (mean estimate $\pm 1.96 \mathrm{SE}$. A significant positive effect occurs at each time period in which the band is "above" the zero line. Red band mean estimate $\pm 1.96 \mathrm{SE}$ is larger than zero (equals a significant positive effect with $p \leq 0.05$ ), orange band: mean estimate $\pm 1.645 \mathrm{SE}$ is larger than zero (equals a significant positive effect with $p \leq 0.1$ ) 

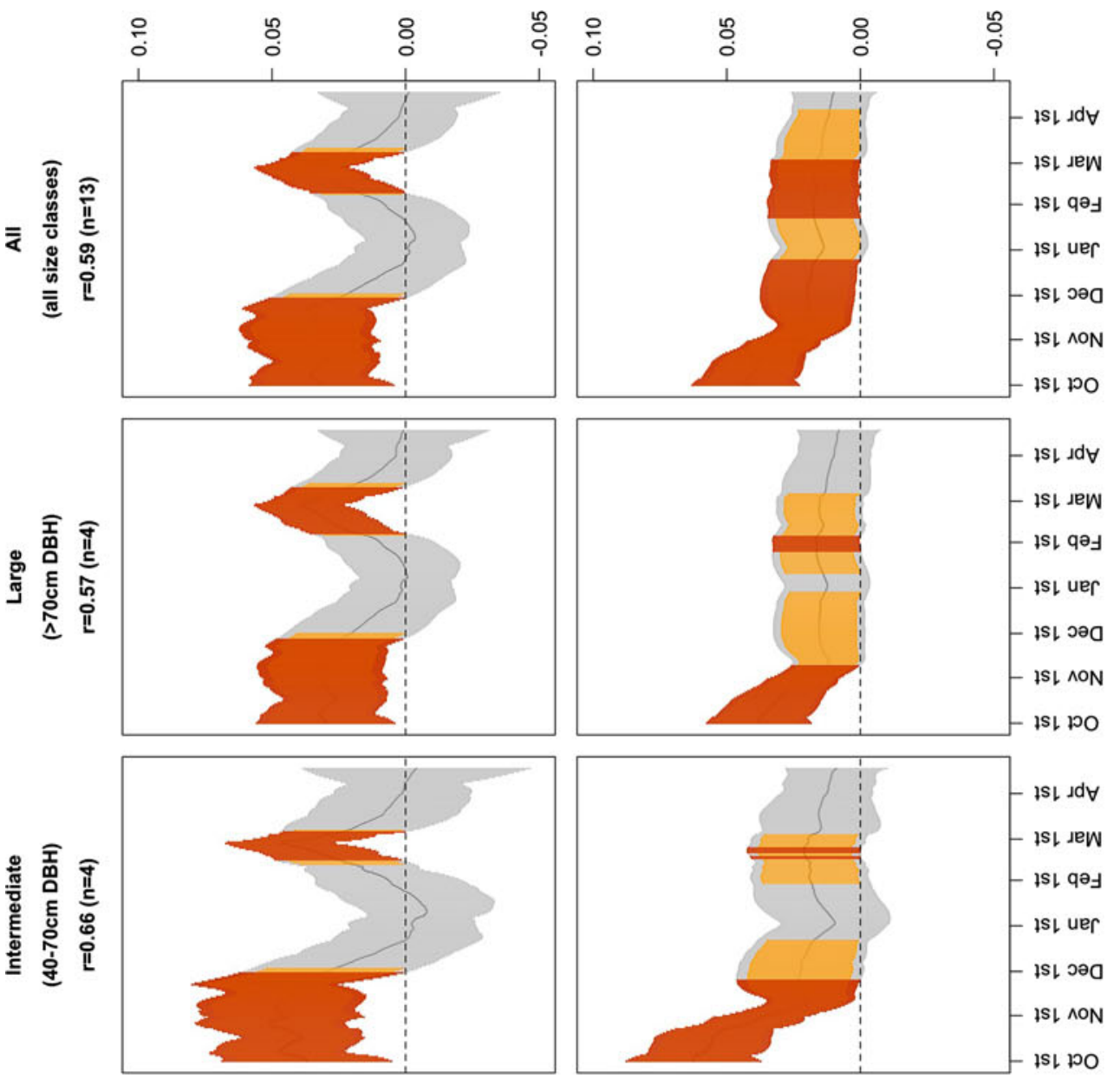

Is! dd

ISL JeW

ไsเ qә]

jsł uer

เsเ วอด

ISL $\wedge O N$

ISL
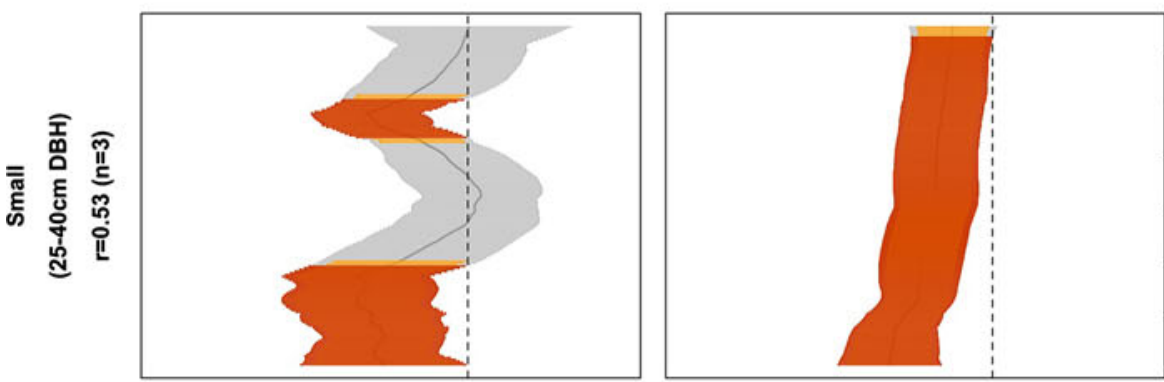

Is! $d \mathrm{~d} \forall$

ISL JeW

เs! qә]

ISL Uer

ISเ כอव

ISL $\Lambda$ ON

ISI toO

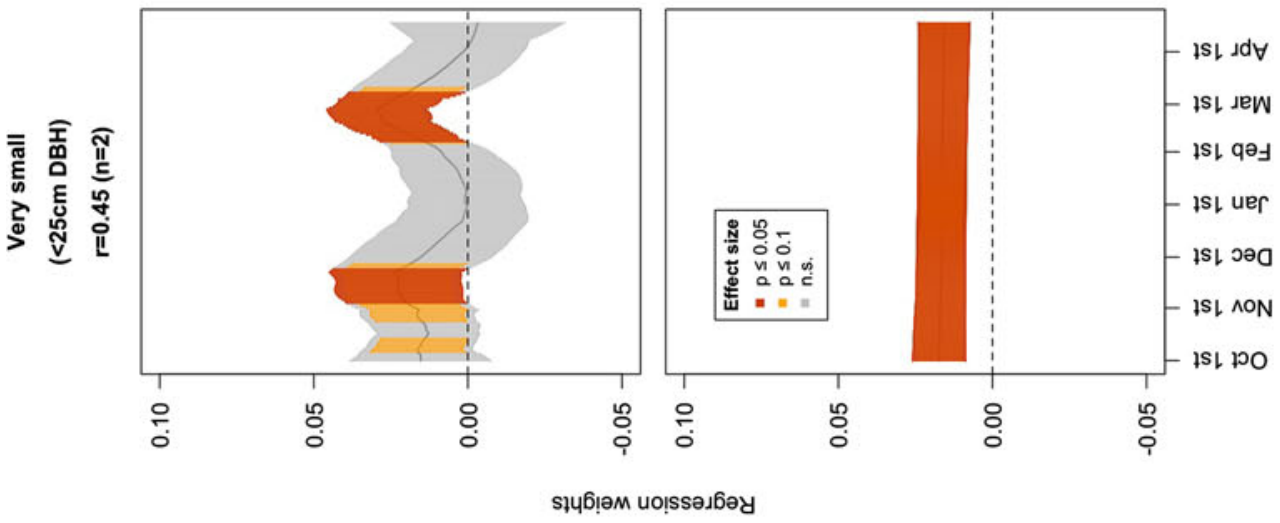

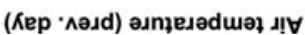

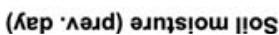


Thus, a wide range of tree life stages from seedling to forest giant seem to react similarly to this temperature threshold-at least within the centre of the kauri growth range. Beside this "upper" temperature threshold of $17.5^{\circ} \mathrm{C}$, the growth period can also be characterized by a daily minimum temperature of ca. $8^{\circ} \mathrm{C}$, that is more likely to act as an ecophysiological threshold for tree growth (Körner and Paulsen 2004). In any case, it is rather surprising that kauri growing in a mild subtropical climate have a temperature-controlled dormancy period that is known for many boreal and temperate climates and along treeline ecotones (e.g. Rossi et al. 2008; Gruber et al. 2009; Hughes et al. 2011 for a review).

\section{Climate responses of different-sized trees}

Smaller trees $(\mathrm{DBH}<40 \mathrm{~cm})$ showed different climate responses than large trees (Fig. 7). Particularly soil moisture appears to be more important for smaller kauri, which may be related to differences in the root architecture between small and large trees (Ecroyd 1982). However, for the smaller trees, the unexplained residual variance is relatively high, indicating that a fairly large amount of nonclimatic factors not recognized here may effect tree growth, e.g. internal carbon allocation (Genet et al. 2009) or competition processes (Schweingruber 1996). This points towards a weaker climate response of smaller trees and is in line with our correlation function analysis (annual resolution).

Trees of all size classes show time-dependent climate responses (Fig. 7): the warmer the air and the wetter the soil of the previous day, the higher the daily growth rate. Both temperature and soil moisture are known as important drivers of xylem growth (Kozlowski and Pallardy 1997). The lag effect of 1 day suggests a somewhat delayed response of the cambium and contrasts previous findings demonstrating a quick cambial response to environmental variability (Deslauriers and Morin 2005). We found no direct effect of solar radiation on tree growth, contrary to the hypothesis by Fowler et al. (2000).

The simple approximation for xylem growth (SRI) used here is likely to contain non-growth-related circumference changes-and xylem growth may also occur during phases of stem shrinkage as noted by Downes et al. (1999). However, since long-lasting dry spells never occurred at our site (max. 21 consecutive days of $<1 \mathrm{~mm}$ daily precipitation), this "shrinkage" error almost certainly plays a much smaller role than in areas that experience prolonged drought periods (Buell et al. 1961; Bormann and Kozlowski 1962).

The here found positive effect of daily temperature and soil moisture on tree growth is not reflected by the correlation functions (annual resolution). Seasonal precipitation (entire season) and temperature (autumn only) are even negatively correlated with current year annual growth. Such counter-intuitive negative correlations were already noted by Buckley et al. (2000) and may be at least partly explained by a lag-effect of 1 year with warm-wet conditions of the previous spring leading to above-average growth in the current year (Fig. 2). However, since the correlation analysis relates annual growth increments to monthly mean climate over the last century, it may be possible that above-average annual growth coincides with below-average monthly temperature and precipitation while within one particular season both temperature and soil moisture can have a positive effect on daily tree growth.

Interestingly, the observed different climate responses of small versus large trees are clearly visible at the annual time scale (correlation analysis), and to a lesser extent at the daily time scale (Kalman filter regression), but largely hidden when looking at dendrometer data in monthly resolution (this study and Fowler et al. 2005).

\section{Perspectives and limitations}

This study focuses on the size dependency of the climategrowth relationship of kauri at different temporal scales. The observed differences between small and large trees at annual and daily time scales can be used to enhance the climate signals in kauri-based climate reconstructions by stripping any "small-tree material" from the chronology. To this end, the distance to the pith of any given ring can be roughly estimated using its curvature (Duncan 1989) and the entire ring excluded when this distance falls below the $20-\mathrm{cm}$ threshold corresponding to $40 \mathrm{~cm} \mathrm{DBH}$.

It should be noted that the data presented here on daily growth and climate conditions across one season are used to explore potentially different reactions of small versus large kauri; however, it should not be confused with, and cannot be used for, the translation of long-term tree-ringdata into climate information: First, daily growth is modelled in response to two climate factors (air temperature and soil moisture), hence, it is not possible to reconstruct both climate factors from records of past daily growth. Second, long-term records of past daily growth are not available. Third, both the observation period (one particular season) and sample size (13 trees) are far too short to infer climate history from growth patterns.

The dendrometer bands used here seem to be better suited than point dendrometers to capture the variable growth patterns of kauri that are known from stem cross sections of logging relics (Boswijk et al. 2006). In addition, dendrometer bands also average non-growth processes like hydration that may vary strongly at different parts of the stem (Kozlowski and Winget 1964; Fritts 1976). However, 
a disadvantage is the larger vulnerability of the bandsespecially for larger trees where the likelihood increases that the relatively long bands may be disturbed by resin exudations or bark flaking. Therefore, a large maintenance effort is required to ensure a high data quality, in our case field visits on a weekly basis. Both, dendrometer bands and point dendrometers are limited in their ability to capture the "pure" xylem growth — and the here used approximation by Downes et al. (1999) is certainly an oversimplification of the combined processes comprising positive changes in xylem growth and positive and negative changes due to water stress.

The analysis presented here may be extended by a spatial component that may elucidate how tree competition influences tree growth and thus the climate signals stored within the annual rings. Therefore, future research may focus on larger sample sizes of trees, a wider range of trees including smaller trees, and also additional sites at more extreme locations of the kauri growth range, e.g. the highest elevation kauri forests at Mt. Moheau, Coromandel peninsula. In addition, more detailed physiological and environmental sensors, e.g. sap flow measurements or a soil moisture sensor network may allow for a more mechanistic understanding of the climate-growth relationship (Zweifel et al. 2006).

\section{Conclusions}

Five main conclusions can be drawn from our field study:

1. The seasonal climate-growth relationship of kauri is size dependent. Small trees with less than $40 \mathrm{~cm} \mathrm{DBH}$ show different climate responses and contain a weaker climate signal.

2. For kauri of all sizes, most of the xylem formation occurs during the austral spring months October and November, i.e. the time where the ENSO signal on New Zealand climate is usually strongest (Gordon 1986).

3. Kauri dormancy coincides with a period characterized by maximum weekly air temperatures below ca. $17-18{ }^{\circ} \mathrm{C}$ and daily temperature minima below ca. $8{ }^{\circ} \mathrm{C}$.

4. Daily kauri growth rate (measured as stem radial increment [SRI], Downes et al. 1999) is mainly influenced by air temperature and soil moisture of the previous day with the strength of this relationship being highly time-varying.

5. The flexible Kalman filter regression is a powerful tool to reveal time-dependent influences on seasonal tree growth.

Albeit these findings have to be confirmed for additional sites of the kauri growth range, the currently available data from different temporal scales suggest that small kauri contain weaker climate signals than large trees. Therefore, "small-tree material" of whatever source (archaeological or modern trees) should be identified, for example using distance-to-pith estimations based on ring curvature (Duncan 1989). An omission of this "small-tree material" from longterm tree-ring chronologies may enhance the reliability of the resulting kauri-based climate reconstructions.

Acknowledgments We would like to thank Gretel Boswijk, Jürgen Groeneveld and Sebastian Leuzinger for helpful discussions and Peter Crossley, George Perry and Angela Belchior Wunder for their help with the field work. Furthermore, we would like to thank the Editorin-Chief Ulrich Lüttge and two anonymous reviewers for helpful comments on the manuscript. The first author acknowledges funding by the Swiss National Science Foundation SNF (post-doctoral fellowship PBEZ2-118902). Financial support for this research was provided by the New Zealand Foundation for Research, Science and Technology (FRST contract UOAX0714).

\section{References}

Bartels R (1982) The rank version of von Neumann's ratio test for randomness. J Am Stat Assoc 77:40-46

Bieleski RL (1959) Factors affecting growth and distribution of kauri (Agathis australis Salisb.) III. Effect of temperature and soil conditions. Aust J Bot 7:279-294

Biondi F, Waikul K (2004) DENDROCLIM2002: a C++ program for statistical calibration of climate signals in tree-ring chronologies. Comput Geosci 30:303-311

Bormann FH, Kozlowski TT (1962) Measurements of tree ring growth with dial gage dendrometers and vernier tree ring bands. Ecology 43:289-294

Boswijk G, Fowler A, Lorrey A, Palmer J, Ogden J (2006) Extension of the New Zealand kauri (Agathis australis) chronology to 1724 BC. The Holocene 16:188-199

Buckley B, Ogden J, Palmer J, Fowler A, Salinger J (2000) Dendroclimatic interpretation of tree-rings in Agathis australis (kauri). 1. Climate correlation functions and master chronology. J Roy Soc New Zeal 30:263-275

Buell MF, Buell HF, Small JA, Monk CD (1961) Drought effect on radial growth of trees in the William L. Hutcheson Memorial Forest. Bullet Torrey Bot Club 88:176-180

Büntgen U, Tegel W, Nicolussi K, McCormick M, Frank D, Trouet V, Kaplan JO, Herzig F, Heussner K-U, Wanner H et al (2011) 2500 years of European climate variability and human susceptibility. Science 331:578-582

Carrer M, Urbinati C (2004) Age-dependent tree-ring growth responses to climate in Larix decidua and Pinus cembra. Ecology 85:730-740

Cook ER, Johnson AH (1989) Climate change and forest decline: a review of the red spruce case. Water Air Soil Pollut 48:127-140

Cook ER, Buckley BM, Palmer JG, Fenwick P, Peterson M, Boswijk G, Fowler A (2006) Millennia-long tree-ring records from Tasmania and New Zealand: a basis for modelling climate variability and forcing, past, present and future. J Quat Sci 21:689-699

De Luis M, Novak K, Cufar K, Raventos J (2009) Size-mediated climate-growth relationships in Pinus halepensis and Pinus pinea. Trees 23:1065-1073

Deslauriers A, Morin H (2005) Intra-annual tracheid production in balsam fir and the effect of meteorological variables. Trees 19:402-408 
Deslauriers A, Morin H, Urbinati C, Carrer M (2003) Daily weather response of balsam fir (Abies balsamea (L.) Mill.) stem radius increment from dendrometer analysis in the boreal forests of Québec (Canada). Trees 17:477-484

Dorado Liñán I, Gutiérrez E, Heinrich I, Andreu-Hayles L, Muntán E, Campelo F, Helle G (2011) Age effects and climate response in trees: a multi-proxy tree-ring test in old-growth life stages. Eur J For Res. doi:10.1007/s10342-011-0566-5

Downes G, Beadle C, Worledge D (1999) Daily stem growth patterns in irrigated Eucalyptus globulus and E. nitens in relation to climate. Trees 14:102-111

Duncan RP (1989) An evaluation of errors in tree age estimates based on increment cores in Kahikatea (Dacrydium dacrydiodes). New Zeal Nat Sci 16:31-37

Ecroyd CE (1982) Biological flora of New Zealand 8. Agathis australis (D. Don) Lindl. (Araucariaceae) Kauri. New Zeal J Bot 20:17-36

Esper J, Niederer R, Bebi P, Frank D (2008) Climate signal age effects-evidence from young and old trees in the Swiss Engadin. For Ecol Manag 255:3783-3789

Forster T, Schweingruber FH, Denneler B (2000) Increment puncher-a tool for extracting small cores of wood and bark from living trees. IAWA J 21:169-180

Fowler A, Boswijk G (2001) Tree-ring analysis of kauri (Agathis australis) from Huapai Scientific Reserve, Huapai, Auckland. New Zealand Tree-Ring Site Report No. 6, University of Auckland, Department of Geography Working Paper No. 13. ISBN 0-908672-91-8

Fowler A, Palmer J, Salinger J, Ogden J (2000) Dendroclimatic interpretation of tree-rings in Agathis australis (kauri): 2. Evidence of a significant relationship with ENSO. J Roy Soc New Zeal 30:277-292

Fowler A, Boswijk G, Ogden J (2004) Tree-ring studies on Agathis australis (kauri): a synthesis of development work on Late Holocene chronologies. Tree-Ring Res 60:15-29

Fowler A, Lorrey A, Crossley P (2005) Seasonal growth characteristics of Kauri. Tree-Ring Res 61:3-19

Fowler AM, Boswijk G, Gergis J, Lorrey A (2008) ENSO history recorded in Agathis australis (kauri) tree rings. Part A: kauri's potential as an ENSO proxy. Int J Climatol 28:1-20

Fowler AM, Boswijk G, Lorrey AM, Gergis J, Pirie M, McCloskey SPJ, Palmer JG, Wunder J (2012) Multi-centennial tree-ring record of ENSO-related activitiy in New Zealand. Nat Clim Chang. doi:10.1038/NCLIMATE1374

Fritts HC (1976) Tree rings and climate. Academic Press, London

Genet H, Bréda N, Dufrêne E (2009) Age-related variation in carbon allocation at tree and stand scales in beech (Fagus sylvatica L.) and sessile oak (Quercus petraea (Matt.) Liebl.) using a chronosequence approach. Tree Physiol 30:177-192

Gordon ND (1986) The Southern Oscillation and New Zealand weather. Mon Weather Rev 114:371-387

Gruber A, Zimmermann J, Wieser G, Oberhuber W (2009) Effects of climate variables on intra-annual stem radial increment in Pinus cembra (L.) along the alpine treeline ecotone. Annu For Sci 66-503. doi:10.1051/forest/2009038

Harvey AC (1984) A unified view of statistical forecasting procedures. J Forecast 3:245-275

Harvey AC (1989) Forecasting structural time series models and the Kalman filter. Cambridge University Press, Cambridge

Heinrich I, Weidner K, Helle G, Vos H, Lindesay J, Banks JCG (2009) Interdecadal modulation of the relationship between ENSO, IPO and precipitation: insights from tree rings in Australia. Clim Dyn 33:63-73. doi:10.1007/s00382-009-0544-5
Hughes MK, Swetnam TW, Diaz HF (eds) (2011) Dendroclimatology. Progress and prospects. Developments in paleoenvironmental research, vol 11. Springer, Dordrecht

Hurvich CM, Tsay CL (1989) Regression and time series modeling in small samples. Biometrika 76:297-307

Kalman RE (1960) A new approach to linear filtering and prediction problems. Trans ASME J Basic Eng 82(Series D):35-45

Körner C, Paulsen J (2004) A world-wide study of high altitude treeline temperatures. J Biogeogr 31:713-732

Kozlowski TT, Pallardy SG (1997) Growth control in woody plants. Academic Press, San Diego

Kozlowski TT, Winget CH (1964) Diurnal and seasonal variation in radii of tree stems. Ecology 45:149-155

Mirams RV (1951) A study of some of the factors concerned in the natural regeneration of kauri. Ph.D. thesis, Auckland University

Mullan AB (1995) On the linearity and stability of Southern Oscillation-climate relationships for New Zealand. Int J Climatol 15:1365-1386

Niinemets Ü, Sparrow A, Cescatti A (2005) Light capture efficiency decreases with increasing tree age and size in the southern hemisphere gymnosperm Agathis australis. Trees 19:177-190

Palmer J, Ogden J (1983) A dendrometer band study of the seasonal pattern of radial increment in kauri (Agathis australis). New Zeal J Bot 21:121-126

R Development Core Team (2011) R: a language and environment for statistical computing. R Foundation for Statistical Computing, Vienna, Austria. ISBN: 3-900051-07-0. http://www.R-project.org

Rossi S, Deslauriers A, Anfodillo T, Carrer M (2008) Age-dependent xylogenesis in timberline conifers. New Phytol 177:199-208

Schweingruber FH (1996) Tree rings and environment. Dendroecology, Haupt Berne

Thomas GM, Ogden J (1983) The scientific reserves of Auckland University. I. General introduction to their history, vegetation, climate and soils. Tane 29:143-161

Vaganov EA, Anchukaitis KJ, Evans MN (2011) How well understood are the processes that create dendroclimatic records? A mechanistic model of the climate control on conifer tree-ring growth dynamics. In: Hughes MK, Swetnam TW, Diaz HF (eds) Dendroclimatology. Progress and prospects. Developments in paleoenvironmental research, vol 11. Springer, Dordrecht

Van Deusen P (1990) Evaluating time-dependent tree ring and climate relationships. J Environ Qual 19:481-488

Viera J, Campelo F, Nabais C (2009) Age-dependent responses of tree-ring growth and intra-annual fluctuations of Pinus pinaster to Mediterranean climate. Trees 23:257-265

Visser H (1986) Analysis of tree-ring data using the Kalman filter technique. IAWA Bulletin 7:289-297

Visser H, Molenaar J (1988) Kalman filter analysis in dendroclimatology. Biometrics 44:929-940

Visser H, Büntgen U, D’Arrigo R, Petersen AC (2010) Detecting instabilities in tree-ring proxy calibration. Clim Past 6:367-377

Warren S, Eastman RM, Hahn CJ (2007) A survey of changes in cloud cover and cloud types over land from surface observations, 1971-96. J Clim 20:717-738

Wunder J, Perry GLW, McCloskey SPJ (2010) Structure and composition of a mature kauri (Agathis australis) stand at Huapai Scientific Reserve, Waitakere Range New Zealand TreeRing Site Report No. 33, University of Auckland, School of Environment Working Paper No. 39. ISBN: 978-0-9582805-6-3

Zweifel R, Zimmermann L, Zeugin F, Newbery DM (2006) Intraannual radial growth and water relations of trees: implications towards a growth mechanism. J Exp Bot 57:1445-1459 